\title{
Nursing in the hospital accreditation process: practice and implications in the work quotidian ${ }^{1}$
}

\author{
Bruna Figueiredo Manzo ${ }^{2}$ \\ Helen Cristiny Teodoro Couto Ribeiro ${ }^{3}$ \\ Maria José Menezes Brito ${ }^{4}$ \\ Marília Alves ${ }^{5}$
}

\begin{abstract}
The aim of this study was to investigate the role and influence of nursing in the hospital accreditation process. It is a qualitative study, conducted in a private hospital of Belo Horizonte. The study subjects were nine nurses and 15 nursing technicians. Data collection was through semi-structured interviews, which were subjected to content analysis. The results showed that the role of the nursing team in the accreditation involves care, administrative, educational and research issues. The study subjects presented different perceptions regarding the influence of the accreditation process in their work. The positive aspects of personal growth and valorization of the curriculum were highlighted as well as negative aspects such as stress and little professional valorization. Therefore, it is necessary that the professionals understand the logic of the process and act with a view to the interdisciplinarity and overcoming the fragmentation of care, thus achieving integral healthcare and the quality of care desired.
\end{abstract}

Descriptors: Nursing; Quality of Health Care; Accreditation.

\footnotetext{
${ }^{1}$ Paper extracted from Master's Thesis "Acreditação Hospitalar na perspectiva dos profissionais de saúde", presented to Escola de Enfermagem, Universidade Federal de Minas Gerais, Belo Horizonte, MG, Brazil.

2 RN, Doctoral student in Nursing, Escola de Enfermagem, Universidade Federal de Minas Gerais, Belo Horizonte, MG, Brazil. E-mail: brunaamancio@yahoo.com.br.

3 RN, Master's student in Nursing, Escola de Enfermagem, Universidade Federal de Minas Gerais, Belo Horizonte, MG, Brazil. E-mail: helenctcouto@yahoo.com.br.

${ }^{4}$ RN, Ph.D. in Administration, Adjunct Professor, Escola de Enfermagem, Universidade Federal de Minas Gerais, Belo Horizonte, MG, Brazil. E-mail: brito@enf.ufmg.br.

${ }^{5}$ RN, Ph.D. in Nursing, Full Professor, Escola de Enfermagem, Universidade Federal de Minas Gerais, Belo Horizonte, MG, Brazil. E-mail: marilix@ufmg.br.
}

Corresponding Author:

Bruna Figueiredo Manzo

Rua Professor Baroni, 235, Apto. 601

Bairro: Gutierrez

CEP: 30441-180, Belo Horizonte, MG, Brasil

E-mail: brunaamancio@yahoo.com.br 


\title{
A enfermagem no processo de acreditação hospitalar: atuação e implicações no cotidiano de trabalho
}

Os objetivos neste estudo foram conhecer a atuação e as influências da enfermagem no processo de acreditação hospitalar. Trata-se de pesquisa qualitativa, realizada em um hospital privado de Belo Horizonte, MG. Esta pesquisa ficou composta por nove enfermeiros e quinze técnicos de enfermagem. Os dados foram coletados por meio de entrevistas com roteiro semiestruturado, submetidas à análise de conteúdo. Os resultados mostraram que a atuação da enfermagem na acreditação envolve questões assistenciais, administrativas, educativas e de pesquisa. Os sujeitos da pesquisa apresentaram percepções diversas sobre a influência do processo de acreditação no seu trabalho. Foram destacados aspectos positivos como crescimento pessoal e valorização do currículo e aspectos negativos como estresse e pouca valorização profissional. Assim, é necessário que os profissionais entendam a lógica do processo, atuem com vistas à interdisciplinaridade e superação da fragmentação da assistência, alcançando assim o cuidado integral e a qualidade assistencial desejada.

Descritores: Enfermagem; Qualidade da Assistência à Saúde; Acreditação.

\section{La enfermería en hospital en proceso de acreditación: su papel y las consecuencias en el trabajo diario}

\begin{abstract}
Este estudio investigó el papel y la influencia de la enfermería en el proceso de acreditación de hospitales. Se trata de un estudio cualitativo realizado en un hospital en Belo Horizonte. Los sujetos del estudio fueron 09 enfermeras y 15 técnicos de enfermería. Los datos fueron recolectados a través de entrevistas semiestructuradas, las que fueron sometidas a análisis de contenido. Los resultados mostraron que la actuación de la enfermería en el proceso de acreditación implica cuestiones relacionadas con la atención, administración, educación e investigación. Los profesionales tenían percepciones diferentes acerca de la influencia del proceso de acreditación en su trabajo. Se destacaron aspectos positivos como el crecimiento personal y el desarrollo del currículo; los negativos fueron estrés y poco desarrollo profesional. Por lo anterior es necesario que los profesionales entiendan la lógica del proceso y actúen con una finalidad interdisciplinaria superando la fragmentación en el cuidado, logrando así la atención integral y la calidad de la atención.

Descriptores: Enfermería; Calidad de la Atención de Salud; Acreditación.
\end{abstract}

\section{Introduction}

The concept of quality in healthcare is not simple nor univocal, but complex and polyvalent. Even with the growing interest in defining quality in recent years, this task still represents a challenge for the actors who operate in the healthcare field, who have not reached an agreement on an appropriate and shared operational definition $^{(1)}$. To be a quality healthcare service it must be integrated in a network, that is, be connected with other healthcare services of different complexities and with other networks such as educational, science and technology, transport and infrastructure, which articulated with the healthcare sector will give support for quality care(2).

The lack of quality in the healthcare services has a serious impact on society and the healthcare systems, manifesting itself in many ways, for example, ineffective services, which do not achieve the expected results; inefficient services, with high costs to achieve the same result; geographically, economically, culturally or socially inaccessible services, reflecting long waiting lists and dissatisfaction of the users and healthcare professionals. This scenario is caused by 
factors such as lack of prioritization of the quality in the agenda of the healthcare sector; deficiency of regulatory frameworks (technical standards, accreditation and licensing systems, and charters of the rights and duties of patients); formation of low quality professionals inadequate for the management of material, human and financial resources; lack of professional development programs; financial transfer disconnected from the performance and the results of the care, absence of teamwork; paternalistic model of healthcare that does not involve the user in the decision making, and inadequate working conditions ${ }^{(3)}$. In order to overcome this scenario, it is necessary, among other political and social actions, to qualify the management of the healthcare organizations, seeking new tools and management models to achieve success in the performance and results presented to society. To this end, the World Health Organization (WHO) recommends the adoption of accreditation programs, which classify the institutions into levels of quality, promoting learning based on the value that is given to a reality in the face of a reference or standard(4-5).

The accreditation of healthcare services has its origins in the work of the surgeon emeritus at Harvard University Hospital - Dr. Ernest Amory Codman (18691940) - who, deeply committed to the quality of care, helped found the American College of Surgeons (ACS) which, in 1917, developed, from the studies of Codman, a proposal of "Minimum Standards for Hospitals". In 1918, the ACS visited 692 hospitals, of which only 89 met the requirements of these minimum standards, however, in 1950, there were 3,200 hospitals approved. At this time, in 1951, the American College of Internal Medicine, the American Hospital Association, the American Medical Association and the Medical Association of Canada join the ACS to establish the Joint Commission on Accreditation of Hospitals, a nongovernmental, non-profit organization with the aim of offering accreditation(5).

The history of the Brazilian System of Accreditation starts much later, in the late 1980's, when the Pan American Health Organization (PAHO) established a set of standards for the hospitals in Latin America, which if achieved would give the organization the accreditation certification. The Ministry of Health created, in 1997, a national commission of specialists to develop the Brazilian model of accreditation and in 1999, the National Accreditation Organization (NAO) was formed, being a non governmental, non-profit organization mandated to coordinate the accreditation system ${ }^{(6)}$. In this year, after the formulation of the PAHO standards and pilot projects in several hospitals in the country, the Manual for Accreditation of Hospitals of Brazil was also published(5). This manual has undergone several revisions and since 2006 the Brazilian Manual for Accreditation of Healthcare Service Provider Organizations (MAB/HSPO) has been published, thus adding other healthcare institutions to the same instrument. The most current version of the MAB/HSPO of the NAO was published in 2010 and represents an essential instrument to guide evaluators and healthcare institutions in the accreditation process $^{(7)}$. The NAO proposes a classification by levels: level 1 , refers to the basic requirements of quality, level 2, refers to the evidence of planning of the care in the organization and level 3, contemplates the policies for continuous improvement in the hospital structures ${ }^{(8)}$.

The effective adherence to hospital accreditation requires the networking of the sectors and their collaborators, since it is considered a complex system in which structures and processes are interconnected in such a way that a component affects the institutional result. In the hospital, the nursing team is critical to a quality program, due to the significant number of professionals and their direct and permanent practice with internal and external clients. The nurse interacts with all the areas of support, with autonomy and coresponsibility, through the instruments of organizational structure, such as internal regulations, organograms, routines, and communication and control systems. Furthermore, since the academic formation the nurse is familiar with management issues, leadership, and the clinical audit, being an educator and a researcher. Having thus, the unique ability to assist the multidisciplinary team during the implementation and monitoring of a process of Accreditation ${ }^{(8-9)}$. Therefore, the accreditation processes are influenced by the nursing actions and at the same time have important implications in the work quotidian of the team.

In light of the considerations presented the following questions arise: What is the role of nursing in the hospital accreditation process? What are the implications of this process for the nursing team? The answers to the questions presented may provide subsidies to expand the discussions and reflections on the participation of nursing in the accreditation process, providing greater adherence of the team in the provision of qualified care. The aim of this study was to investigate the role and influence of nursing in the hospital accreditation process. 


\section{Methodology}

This is a descriptive case study of a qualitative nature. Qualitative studies are applicable to the study of history, of relationships, ideas, beliefs, perceptions and opinions, products of the interpretations that the social subjects make about how they live, construct their artifacts, feel and think ${ }^{(10)}$. The case study aims to investigate contemporary phenomena in their real context and is characterized by a deep and thorough study of one or a few objects, in order to allow broad and detailed knowledge about them ${ }^{(11)}$.

The present study was conducted in a medium-sized private hospital of Belo Horizonte, inaugurated in 2004 with the prospect of being the reference in healthcare quality for all the hospitals in the private system. In 2006 the hospital was accredited at the level of excellence, achieving success in all the stages of the accreditation process. The study included the Inpatient, Surgical and Progressive Care Unit (PCU) sectors, these having been created at the time of inauguration and having participated in the first external audit performed in the hospital. The choice of study subjects was carried out intentionally, using as inclusion criteria the participation of nursing professionals and nursing technicians who had participated in the hospital accreditation process from the first audit. Data collection was conducted through interviews, using a semi-structured script, with at least one professional of each sector. To this end, the criterion of saturation of information was used, which assumes stopping the inclusion of new participants in the study when the data obtained begins to present some redundancy or repetition, with it not being considered relevant to persist in the data collection ${ }^{(12)}$. The research sample totaled 15 nursing technicians and 9 nurses.

The data collected were subjected to content analysis, seeking to reach a deeper understanding of the phenomenon, beyond the merely descriptive scope of the manifest content of the message ${ }^{(13)}$. Two thematic categories were constructed from the results of the analysis process: The role of the nursing team in the hospital accreditation process and the implications of the hospital accreditation process for the hospital nursing team. In order to ensure the anonymity of the research subjects, the interviews were numbered according to the sequence in which they occurred and with an acronym according to the professional respondent, namely $R N$ for nurses and NT nursing technicians. Regarding the ethical aspects, the study was performed taking into account the provisions of Resolution 196/96 of the National
Health Council, which establishes the guidelines and regulatory rules for research involving human subjects, and was approved by the Research Ethics Committee of the Federal University of Minas Gerais, under Protocol No. $2567 / 08$. All the subjects who agreed to participate signed the Terms of Free Prior Informed Consent.

\section{Results and discussion}

\section{The role of the nursing team in the hospital accreditation process}

The study subjects reported that in the accreditation process nursing actions are performed relative both to care and administrative issues, with the latter receiving a greater focus, as its execution is the responsibility of nurses: We implemented the Nursing Care Systematization (NCS) which was fundamental for the continuous improvement of the indicators $\left(\mathrm{RN}_{2}\right)$. The nursing team performs all the Standard Operating Procedures (SOP) and these are reviewed continuously $\left(\mathrm{RN}_{5}\right)$. To organize the patient, to give medication and to check that everything is done correctly (...) to complete all the procedures in accordance with the routine $\left(\mathrm{NT}_{5}\right)$. The nursing team controls the quality and humanization of the service, and tries to provide safe care with the lowest risk to the patient, with the minimum impact. Shorter hospitalization, better care at lower cost $\left(\mathrm{RN}_{1}\right)$.

The nursing team in general has as its essence caring for the human being, individually, within the family and the community, developing important actions that, through the care, are responsible for the comfort, ease and well-being of the patients ${ }^{(14)}$. The leader of this team - the nurse, on the other hand, has to specifically provide conditions for this care to occur in a safe way with quality, through management actions. The interviewees highlighted the management tasks as the prerogatives of the nurse: We are responsible for the appropriate timetable of employees, according to our legislation, I participate in the standardization of medicines and medical records committee $\left(\mathrm{RN}_{4}\right)$. Now we have risk management and we have implemented a spreadsheet for its control. Every time there is an adverse event we put it in the spreadsheet and identify it there: red is severe, orange is moderate, according to the severity. We evaluate the quality indicators and discuss with the team which can be improved $\left(\mathrm{RN}_{1}\right)$.

The administrative practice of the nurse has evolved to adapt to the new requirements presented in each historical, social, political and economic context. In the recent past the nurse was the head of the sector, today the market requires them to be managers of the strategic business unit, with an understanding of the 
whole and not just the traditional part that used to be their responsibility, the nursing(15). This can be seen in the $\mathrm{RN}_{4}$ statement, which mentions participation in committees and evaluation of indicators, extrapolating their sectoral actions, achieving a level of institutional practice. Furthermore, an important role of the nurse that emerged in the accreditation process was the training of the professional, as a strategy for reorganizing the work processes in pursuit of continuous improvement: Training, revision of the SOP, assessment of needs, we are always reviewing some process or routine, always trying to improve $\left(\mathrm{RN}_{1}\right)$. The nursing team conducts training to try to be up to date, passes the information to the team, including the medical team $\left(\mathrm{RN}_{7}\right)$. We only manage to have quality with training so that everyone does things the same way, safely $\left(\mathrm{NT}_{4}\right)$.

During the undergraduate education the professionals receive a basic and fundamental formation to perform their work, however, at the end of this and throughout their professional lives the knowledge and skills remain under construction and are remodeled. Thus, as seen in the $\mathrm{NT}_{4}$ statement continuing education is important to allow updating of the quotidian practices performed by the professional and to construct relationships and processes that are good for the teams as well as the institutional practices. Thus, continuing education in healthcare is a fundamental strategy so that the work translates into a reflective, critical and purposeful practice of transformation, with a view to constantly improving the quality of the healthcare actions and services provided to the patients ${ }^{(16)}$. Accordingly, in the process of professional improvement of the nurse it is essential to emphasize leadership. In a recent study conducted in 14 hospitals certified by the NAO and by the Joint Commission International (JCI) in the municipality of São Paulo, leadership was found to be the most important skill and more present in the nursing managers of these accredited institutions, in the view of their hierarchical superiors(17). However, during the formation of the nursing professionals the technical aspects are valued more highly at the expense of managerial aspects, which are necessary for nurses when they are inserted into the practice and need to make decisions that will impact on the institutional quality and results.

Moreover, the nursing team and especially the nurse in the accreditation process also perform actions of a scientific nature, as highlighted: We also participate in a research group and clinical discussion $\left(\mathrm{RN}_{6}\right)$. The participation of the nursing team both in developing research and in the clinical discussions of patients is critical for the quality of the care. However, nursing research is not encouraged in the hospital organizations, with the amount being much lower when compared to studies developed by the Universities and Schools of Nursing(18). Thus, it can be noted that the role of nursing in the accreditation process, according to the study subjects, is similar to the process of nursing work, reported in the literature, which involves actions directed toward the dimensions of care, administration/management, teaching and research. However, it can be emphatically seen in the statements of the subjects that the management role, particular to the nurses, prevails in the accreditation process to the detriment of the role exercised by the professional nursing technician.

\section{Implications of the hospital accreditation process for the nursing team}

The perceptions of the professionals regarding the implications of the accreditation process in their quotidian work differed, with positive and negative perceptions. The positive aspects were related to the possibility of personal growth and valorization of the curriculum and the negative aspects to the stress and high pressure, as shown: It's good for the professional. To work in a hospital that has the NAO is good for the CV. I think this is a positive point, and a negative one is the stress $\left(\mathrm{NT}_{5}\right)$. In a way, the employee grows. Because they stop being only involved with the medical prescription, and start to think critically. But at the same time, they have to divide themselves, to spread around. They have to make a long-standing commitment to the NAO, the paperwork and all the bureaucracy of care. It is very heavy, and because of this the patient loses, and the employee leaves here stressed, because he always has the feeling "I did not manage to do everything". This demotivates the employee $\left(\mathrm{RN}_{3}\right)$.

The positive aspects of the accreditation process are still linked to the feelings of pride and satisfaction, as the nurses feel responsible for this achievement and the valorization of the hospital: We are very happy when the hospital passes the audit, the hospital was accredited and we were involved, out there this will make a difference for us ( $\left.\mathrm{NT}_{15}\right)$. In this respect the quality is everything that adds value to the work or the relationships ${ }^{(19)}$ and is directly linked to the organizational results and to the professional and personal development.

The issue of professional security was also mentioned by the interviewees as a positive aspect. The professionals stated that the employee inserted into an accredited service feels better prepared to meet the needs of the clients, due to the offer of material, 
technical and human resources best qualified for the standardization of routines and better organization. You have the security of working in a recognized company, a company that is continuously seeking to improve and that also gives us the security to do a good job $\left(\mathrm{TE}_{15}\right)$. From the moment certain issues are standardized (...) they begin to be beneficial because it is a better environment to work. Not that the accreditation mitigates any of the problems, they occur in the same way, but from the moment that certain things are standardized, this helps $\left(\mathrm{RN}_{4}\right)$.

The professionals also reported that the accreditation process provides a favorable organizational climate, conducive to strengthening the relationships: The hospital will aim for a climate that is good for the professional, that there is a good relationship with the internal clientele, it will also be concerned with employee satisfaction, with the conditions of their work $\left(\mathrm{NT}_{3}\right)$. In this quest for accreditation we end up becoming a family $\left(\mathrm{NT}_{13}\right)$. I think I was more involved because we have a group of nurses, a good level of friendship, of companionship, of helping one another, of cooperation, we end up growing $\left(\mathrm{RN}_{3}\right)$. The improvement in the working conditions is conducive to a relationship of growth, enthusiasm and pleasure for the staff, facilitating the efficient development of the work, with quality, in an environment of satisfaction and happiness ${ }^{(20)}$.

Other statements show professional maturity as a positive aspect of the accreditation process, providing exchanges of experiences and allowing more opportunities in the labor market. Here, in five years I grew more than in the 10,12 years that I worked elsewhere, precisely because this hospital has processes, has requirements, because they believe in this. The market has a lack of employees qualified in this process. I believe that in the future, these professionals will have more job opportunities $\left(\mathrm{RN}_{6}\right)$. It is a process that provides conditions for professional development, opening the field for these professionals $\left(\mathrm{RN}_{9}\right)$. Regarding this aspect, the implementation of an accreditation process must mobilize the institutional resources for the construction of a new paradigm, for this, standards, procedures, processes and methodologies are developed in order to assure the patients. Thus, the change in attitude is the result of a construction process based on the sharing of information, with the clear definition of aims and goals ${ }^{(8)}$.

In relation to the negative perceptions about the accreditation, the lack of valorization is a complaint that emerged from the statements. The professionals felt undervalued in the face of the challenge experienced, they reported that their mistakes are noticed and criticized, while they do not receive any praise for the goals and victories achieved: I think that the professional feels stressed with such pressure, at all times they are always pressured for an error, sometimes they do not get much praise for something they did well. Errors are always being sought $\left(\mathrm{RN}_{9}\right)$. The accreditation process aims to change this culture of finding the culprit, with mistakes seen as a systemic event, which occurred due to diverse factors. However, the tools of quality are sometimes used to attribute fault, fear and to develop control over people and not over the process of work and training ${ }^{(19)}$.

The nursing team also highlighted an uneven pressure in relation to the different categories, with this scenario being unfavorable for quality healthcare, since this overloads the nursing team: The team does not participate in general, so that the nursing is just plugging the hole that the others could not resolve. The medical team participate very little, practically nothing $\left(\mathrm{RN}_{4}\right)$. From my point of view we see more pressure in the nursing (...) I do not see the physicians. At least in the training I did not realize they were participating there, no! So I think that there is greater pressure for the nursing team $\left(\mathrm{NT}_{5}\right)$. The nursing team as a whole is under a great deal of pressure. The majority of the indicators are evaluated by us (...). It is still very focused on the Nursing. This may have to change a little, because the responsibility for all the changes, both good and bad, is put on us. But it is not all down to us, not everything is resolved by the nursing team $\left(\mathrm{RN}_{9}\right)$.

The interviewees mentioned the lack of integration of the multidisciplinary team and reported the inexistence of cohesion among the professionals, even though they should be united in the pursuit of excellence of the services. The situation revealed is contrary to the principles advocated by the NAO, regarding interdisciplinary teamwork and integral healthcare. From this logic the disinterest of the multidisciplinary team, particularly the medical staff, undermines the whole accreditation process, since without the support of these professionals the evaluation process of the healthcare quality has a limited value(21). Thus, the effective participation of all the professional categories of the organization is extremely important for the pursuit of excellence of the healthcare services(4).

The scenario permeated by overload and pressure for the commitment to the institutional goals related by the study subjects is often associated with increased remuneration: For us professionals it does not make a difference, nothing has changed! Because you gained the title but do not get a salary increase. It does not improve. With or without NAO nothing changes. I think it's worse to have NAO: the pressure is great $\left(\mathrm{NT}_{10}\right)$. When we started, they said that when we gain the NAO, the salary would increase (...). They told us we would have a $14^{\text {th }}$ yearly payment if we got the title, 
now they say that it is a lie, that it was us the technicians who created this. Who created it? Why would we create such a thing, a lie? No! It's because it was actually said! Then we started to pressure ( $\mathrm{NT}_{6}$ ). Accordingly, in the accreditation process the institution needs to formulate a system of rewards and recognition for the efforts of its collaborators, to stimulate and motivate the people for the commitment to quality and excellence in the services provided(22).

It is worth noting that another negative aspect raised by the interviewees was the implementation of accreditation as a top to bottom process, i.e. the senior management decided on its implementation without previously informing the team of professionals of the proposal: It was put to us that the hospital would have to be accredited, full stop $\left(\mathrm{RN}_{2}\right)$. Things changed from one day to the next without us knowing what was happening $\left(\mathrm{NT}_{12}\right)$. These findings confirm that because the collaborators do not understand the process, they ignore its aims and proposals, demonstrating, as a natural consequence, opposition or resistance to the new method(21). In this way, it is presupposed that the way in which the professionals, and specifically in this study the nursing team, experience the accreditation process, contributes to the rupture of an organizational culture, leading to a path that generates or not quality and excellence in the provision of healthcare.

\section{Final considerations}

For the hospital accreditation to bring improvements to the quality of the healthcare requires work with a view to the interdisciplinarity and overcoming the institutional fragmentation of the care, leading the professionals to understand the logic of integral care and, consequently, achieve the desired quality. From this perspective the professional nurses have a pivotal role, together with their teams, in the accreditation process, as they actively participate in decisive, strategic and operational moments. The role of the nursing team involves actions directed toward the dimensions of care, administration/ management, teaching and research. However, it can be seen in the statements of the study subjects that the management role, particular to the nurses, prevails in the accreditation process to the detriment of the role exercised by the professional nursing technician. In fact, the managerial role exercised makes sense, taking into consideration that the accreditation is an instrument and model of management. However, the quality resulting from the accreditation will be reflected mainly in the care quotidian of the patients, which is carried out not only by the nurse or nursing team, but by a multiprofessional team. This scenario highlights important considerations in order to further include the other professional categories in the accreditation process, which, together with the diversity of perspectives, practices and methods, can provide more integral and quality care.

It was possible to observe both positive and negative perceptions. The positive aspects were related to the possibility of professional maturity; pride and satisfaction because they are also responsible for the recognition of the hospital by society; professional security established through routines, standardization and organization of the service regarding material, technical and human resources better qualified and available; an organizational climate conducive to professional learning through the exchange of experiences and the possibility of further opportunities in the labor market. The negatives aspects were related to lack recognition and valorization, including financial, in the face of the challenge experienced, pressure on nursing at the expense of most other categories; limited participation of the multidisciplinary team; and the implementation of the accreditation as something imposed by senior management without sensitization of the professionals.

Thus, from this study it is expected that further research and publications relating to the theme will be carried out, considering the relevance of the role of the professionals in the accreditation process and the influences of this process on the work quotidian, on the quality of care and on the satisfaction of the internal and external clients of the organization. However, this study refers to the case of a hospital, with generalization for other contexts not being possible.

\section{References}

1. Serapioni M. Avaliação da qualidade em saúde. Reflexões teórico-metodológicas para uma abordagem multidimensional. Rev Crítica Ciênc Soc. 2009;85:65-82.

2. Kuschnir R, Lima LD, Baptista TWF, Machado CV. Configuração da rede regionalizada e hierarquizada de atenção à saúde no âmbito do SUS. In: Gondim R, Grabois V, Mendes W organizadores. Qualificação de gestores do SUS. Rio de Janeiro (RJ): ENSP; 2011. p. 121-51.

3. Organización Panamericana de la Salud. Organización Mundial de la Salud. 140a Sesón Del Comité Ejecutivo. Washington [Internet]. 2007 Jun [acesso: 16 ago 2011]. Disponível em: http://www.paho.org/spanish/gov/ce/ ce140-18-s.pdf. 
4. Manzo BF. O processo de acreditação hospitalar na perspectiva de profissionais de saúde. [dissertação de mestrado]. Belo Horizonte (MG): Escola de Enfermagem da Universidade Federal de Minas Gerais; 2009. 98 p.

5. Novaes HM. O processo de acreditação dos serviços de saúde. Rev Adm Saúde. 2007;9(37):133-40.

6. Ministério da Saúde (BR). Agência Nacional de Vigilância Sanitária. Acreditação: a busca pela qualidade nos serviços de saúde. Rev Saúde Pública. 2004;38(2):335-6.

7. Organização Nacional de Acreditação. Manual das Organizações Prestadoras de Serviços de Saúde. Brasília: Organização Nacional de Acreditação; 2010. 164 p.

8. Lima SBS, Erdmann AL. A enfermagem no processo da acreditação hospitalar em um serviço de urgência e emergência. Acta Paul Enferm. 2006;19(3):271-8.

9. Vargas $M A$, Albuquerque $G L$, Erdman $A L$, Ramos FRS. Onde (e como) encontramos a qualidade no serviço de enfermagem hospitalar? Rev Bras Enferm. 2007;60(3):339-43.

10. Minayo MCS. O Desafio do Conhecimento: Pesquisa Qualitativa em Saúde. $10^{a}$ ed. São Paulo: Hucitec; 2007. 269 p.

11. Yin RK. Estudos de caso: planejamento e métodos. $3^{a}$ ed. Porto Alegre: Bookman; 2005. 212 p.

12. Fontanella BJM, Ricas J, Turato ER. Amostragem por saturação em pesquisas qualitativas em saúde: contribuições teóricas. Cad Saúde Pública. 2008;24(1):17-27.

13. Bardin L. Análise de conteúdo. $4^{\mathrm{a}}$ ed. Lisboa: Edições 70; 2009. 229 p.

14. Rocha SMM, Almeida MCP. O processo de trabalho da enfermagem em saúde coletiva e a interdisciplinaridade. Rev. Latino-Am. Enfermagem. 2000;8(6):96-101.

15. Yamauchi NI. Qualidade Gerencial do Enfermeiro. In: Malagutti, W, organizadora. Gestão do Serviço de Enfermagem no mundo globalizado. Rio de Janeiro (RJ): Rubio; 2009. p. 41-59.

16. Ceccim RB. Educação Permanente em Saúde: desafio ambicioso e necessário. Interface Comun Saúde Educ. 2005;9(16):161-8.

17. Furukawa PO, Cunha ICKO. [Profile and competencies of nurse managers at accredited hospitals]. Rev. LatinoAm. Enfermagem. 2011;19(1):106-14.

18. Feldman LB, Cunha ICKO. Identificação dos critérios de avaliação de resultados do serviço de enfermagem nos programas de acreditação hospitalar. Rev. LatinoAm. Enfermagem. 2006;14(4):540-5.
19. Bontato VL. Gestão em saúde: programas de qualidade em hospitais. São Paulo: Icone; 2007. 119 p. 20. Nascimento IJ, Leitão RER, Vargens OCMC. A qualidade dos serviços de Saúde Pública segundo enfermeiros que gerenciam Unidades Básicas de Saúde. Rev Enferm UERJ. 2006;14(3):350-6.

21. Quinto Neto A, Bittar OJN. Hospitais: administração da qualidade e acreditação de organizações complexas. Porto Alegre: Dacasa; 2004. 315 p.

22. Mezomo JC. Gestão da qualidade na saúde: princípios básicos. São Paulo: Loyola; 2001. 301 p. 